\title{
ANALISIS PENGARUH KOMPETENSI TERHADAP KINERJA APARATUR SIPIL NEGARA (ASN) DI KANTOR BAPPEDA KOTA PEKANBARU
}

\author{
Yusriadi \\ Sekolah Tinggi Ilmu Ekonomi Riau \\ E-mail: yusriadi76@gmail.com
}

\begin{abstract}
The human resources of the state civil apparatus are valuable assets for the nation and state, because they are related to government management activities. Almost all lines of social life will certainly be in contact with government regulations and policies. Planning and implementation of government regulations and policies are executed by the state civil apparatus so that if the state civil apparatus has good competence it will have a positive impact on the life of the nation and state. The study aims to determine the effect of competence on the performance of the state civil service apparatus of the State Planning and Development Agency (BAPPEDA) Pekanbaru City. The number of respondents in this study were 50 people who were all BAPPEDA Pekanbaru City employees. By using simple regression analysis the results of competence significantly influence the performance of the results of the t test, $t$ count of (7.234) greater value of t table (1.6772) with a significant level of 0.000 $<0.050$. As for the $R$ square value of 0.522 , it means that competence contributes $52.2 \%$ to employee performance, while $47.8 \%$ is influenced by other factors.
\end{abstract}

Keywords: Competency and Employee Performance

\section{A. PENDAHULUAN}

Kompetensi sumber daya manusia memiliki peranan yang sangat penting dalam mendukung pencapaian dan peningkatan kinerja sebuah organisasi. Seiring dengan lingkungan organisasi yang dinamis dan penuh kompetisi maka perhatian terhadap kompetensi Sumber Daya Manusia (SDM) menjadi sesuatu yang urgen agar sebuah organisasi dapat survive dan growth. Hal ini berlaku bagi semua organisasi apapun termasuk organisasi pemerintah yang peranannya sangat strategis dalam mengelola program-program yang diperuntukkan untuk masyarakat.

Sumber daya manusia Aparatur Sipil Negara (ASN) merupakan aset yang berharga bagi negara, karena berhubungan dengan aktivitas pengelolaan pemerintahan. Hampir disemua lini kehidupan bermasyarakat tentunya akan bersentuhan dengan regulasi dan kebijakan pemerintah. Perencanaan dan pelaksanaan regulasi serta kebijakan pemerintah di eksekusi oleh SDM ASN sehingga jika SDM ASN memiliki kompetensi yang baik akan berdampak positif terhadap kehidupan berbangsa dan bernegara.

Undang-undang No. 5 Tahun 2014 tentang Aparatur Sipil Negara (ASN) mempertegas bahwa salah satu syarat bagi
ASN yang ingin menduduki suatu jabatan harus berdasarkan kompetensi, kualifikasi, kepangkatan, pendidikan dan pelatihan yang sesuai dengan jabatannya. Dengan terpenuhinya persyaratan tersebut diharapkan dapat memberikan pelayanan yang terbaik kepada seluruh masyarakat.

Kritik tentang rendahnya kualitas kerja aparatur sipil negara (ASN) selalu dikaitkan dengan kompetensi personal pegawai. Akan menjadi sebuah persoalan yang sangat serius bagi masyarakat jika kualitas kerja ASN rendah, hal ini akan berdampak terhadap berbagai sektor kehidupan bernegara. ASN merupakan katalisator pembangunan karena kewenangannya yang cukup besar dalam kebijakan anggaran yang diperuntukkan untuk kepentingan rakyat.

$$
\text { Ajib Rakhmanto (2017) }
$$
menyebutkan bahwa kinerja dan profesionalisme ASN yang rendah disebabkan oleh beberapa faktor diantaranya tidak adanya kompensasi yang jelas atas kinerja aparatur, kompetensi atau kemampuannya yang rendah, tidak jelasnya standar kinerja, tidak adanya road map pengembangan ASN, dan tidak adanya standar kompetensi kerja/jabatan ASN. Oleh karenanya upaya mewujudkan pelayanan yang prima dibutuhakn ASN 
yang profesional dan berkompetensi. Kompetensi yang dimaksud adalah penguasaan terhadap pengetahuan dalam bekerja, memiliki keterampilan yang cukup dalam melaksanakan tugas dengan prinsipprinsip efesien dan efektif, serta memilki sikap yang baik yakni jujur, disipilin dan berintegritas.

Rothwell (2000) mengidentifikasi kompetensi yang dibutuhkan seseorang dalam melaksanakan tugas dan tanggung jawabnya meliputi technical competence, managerial competence, interpersonal competence (social/communication competence) dan intellectual competence (strategic competence). Dari beberapa pendapat mengenai kompetensi tersebut dapat dikatakan bahwa kompetensi yang dibutuhkan oleh seseorang dalam suatu organisasi adalah 1) Technical competence (kompetensi teknik) bersifat ketrampilan dan kemampuan khusus yang diperlukan untuk melaksanakan tugas-tugasnya. 2) Managerial competence, kompetensi ini berkaitan dengan kemampuan manajerial dalam hal perencanaan, pengorganisasian, penggerakkan dan pengawasan. 3). Social competence kompetensi sosial adalah kemampuan seseorang dalam berinteraksi dengan pihak lain. 4) Strategic competence adalah kompetensi strategic adalah kemampuan melihat jauh ke depan sehingga dapat merumuskan berbagai kebijakan yang sifatnya strategis. 5) Ethical competence adalah kompetensi etika adalah kemampuan untuk melaksanakan tugas dan tanggung jawabnya dengan pertimbangan etika dan moral.

Badan Perencanaan Pembangunan Daerah Kota Pekanbaru dibentuk berdasarkan Peraturan Daerah Kota Pekanbaru Nomor 9 Tahun 2016 tentang Pembentukan dan Susunan Perangkat Daerah Kota Pekanbaru. Selanjutnya rincian tugas, fungsi dan tata kerja Badan Perencanaan Pembangunan Daerah Kota Pekanbaru diatur dalam Peraturan Walikota Pekanbaru Nomor 116 Tahun 2016 tentang Kedudukan, Susunan Organisasi, Tugas dan Fungsi serta
Tata Kerja Badan Perencanaan Pembangunan Daerah Kota Pekanbaru.

Badan Perencanaan Pembangunan Daerah (BAPPEDA) Kota Pekanbaru merupakan bagian dari organisasi perangkat daerah (OPD) di Pemerintahan yang bertugas melaksanakan penyusunan dan pelaksanaan kebijakan daerah dibidang perencanaan pembangunan daerah. Adapun fungsi BAPPEDA adalah merumusakan kebijakan teknis perencanaan, perkordinasian penyusuanan perencanaan pembangunan, pembinaan dan pelaksanaan tugas dibidang perencanaan pembangunan daerah dan pelaksanaan lain yang diberikan oleh wali kota sesuai dengan tugas, pokok dan fungsinya. Beban kerja yang berat dan strategis membutuhkan SDM ASN yang memiliki kompetensi yang baik agar dapat menyelesaikan tugas-tugas dengan profesional yang dapat memuaskan semua pihak.

Berdasarkan laporan Kinerja Bappeda tahun 2018 yang di akses melalui website http://bappeda.pekanbaru.go.id/ diuraikan tantangan kinerja Pelayanan BAPPEDA Pekanbaru adalah sebagai berikut :

1. Kurangnya komitmen dan keseriusan OPD dalam menyikapi masalah-masalah yang berkaitan dengan perencanaan dan penyelesaiannya sehingga rapat-rapat sering diwakili;

2. Data base perencanaan (e-Planner) belum terintegrasi dengan aplikasi penganggaran (SIPKD) sehingga berpotensi terjadinya inkonsistensi;

3. Masih kurangnya SDM yang memiliki skill dan kompetensi sesuai dengan tugas dan kewajiban utama-nya sebagai perencana;

4. Aplikasi-aplikasi yang berkaitan dengan data dan informasi pembangunan yang dimiliki OPD dilingkungan Pemko Pekanbaru masih parsial belum terintegrasi;

5. Penempatan ASN dalam proses mutasi khususnya untuk posisi jabatan yang menangani perencanaan dan program. 
Secara umum Badan Perencanaan Pembangunan Daerah Kota Pekanbaru telah melaksanakan tugas dalam rangka mencapai tujuan dan sasaran yang telah ditetapkan dalam Rencana Strategis (Renstra) Badan Perencanaan Pembangunan Daerah Kota Pekanbaru Tahun 2017-2022. Pengukuran target kinerja dari sasaran strategis yang telah ditetapkan akan dilakukan dengan membandingkan antara target kinerja dengan realisasi kinerja.

Berdasarkan data yang diperoleh melaui website BAPPEDA Pekanbaru Berikut data Kinerja BAPPEDA Pekanbaru pada tahun 2018, sedangkan untuk tahun 2019 belum ada laporannya.

Tabel - 1

Laporan Kinerja BAPPEDA Kota Pekanbaru Tahun 2018

\begin{tabular}{|c|c|c|c|}
\hline $\begin{array}{l}\mathbf{N} \\
\mathbf{0}\end{array}$ & $\begin{array}{c}\text { Sasaran } \\
\text { Strategis }\end{array}$ & $\begin{array}{c}\text { Indikator } \\
\text { Kinerja }\end{array}$ & Capaian \\
\hline 1 & $\begin{array}{l}\text { Mewujudkan } \\
\text { Reformasi } \\
\text { Birokrasi }\end{array}$ & $\begin{array}{l}\text { Nilai IKM } \\
\text { BAPPEDA } \\
\text { (Renstra) }\end{array}$ & 82 \\
\hline 2 & $\begin{array}{l}\text { Meningkatny } \\
\text { a Kapasitas } \\
\text { dan } \\
\text { Akuntabilitas } \\
\text { Kinerja } \\
\text { Birokrasi }\end{array}$ & $\begin{array}{l}\text { Evaluasi } \\
\text { nilai AKIP } \\
\text { BAPPEDA } \\
\text { (Renstra) }\end{array}$ & B \\
\hline 3 & $\begin{array}{l}\text { Terwujudnya } \\
\text { Keselarasan } \\
\text { dan } \\
\text { konsistensi } \\
\text { Perencanaan } \\
\text { Pembanguna } \\
\text { n Daerah }\end{array}$ & $\begin{array}{l}\text { Tingkat } \\
\text { keselarasan } \\
\text { Dokumen } \\
\text { Perencanaan } \\
\text { Daerah }\end{array}$ & $100 \%$ \\
\hline 4 & $\begin{array}{l}\text { Terlaksanany } \\
\text { a } \\
\text { Pembanguna } \\
\mathrm{n} \quad \text { sesuai } \\
\text { dengan } \\
\text { perencananaa } \\
\mathrm{n}\end{array}$ & $\begin{array}{l}\text { Persentase } \\
\text { Capaian } \\
\text { Kinerja } \\
\text { Indikator } \\
\text { Sasaran } \\
\text { RPJMD } \\
\text { (IKU) } \\
\end{array}$ & $75 \%$ \\
\hline
\end{tabular}

Sumber : LAKIP BAPPEDA Tahun 2018

Dari data tabel-1 diatas dapat diuraikan kinerja BAPPEDA Pekanbaru belum mencapai nilai yang maksimal, dimana pada aspek mewujudkan reformasi birokrasi Eko dan Bisnis (Riau Economics and Business Reviewe) Volume 11, Nomor 1, 27 Maret 2020 nilainya 82 dari 100 sebagai nilai maksimal. Pada aspek Meningkatnya Kapasitas dan Akuntabilitas Kinerja Birokrasi hanya meraih kategori B dari kategori A sebagai kategori terbaik. Pada aspek Terwujudnya Keselarasan dan konsistensi Perencanaan Pembangunan Daerah meraih capaian maksimal yakni $100 \%$, hanya pada aspek Terlaksananya Pembangunan sesuai dengan perencananaan hanya meraih $75 \%$ dari capaian maksimal $100 \%$.

\section{Pengertian Kompetensi}

Spencer dan Spencer (1993) mendefinisikan kompetensi sebagai suatu karakteristik dasar dari seorang individu yang secara sebab akibat berhubungan dengan criterion referenced effective dan/atau kinerja yang tinggi sekali dalam melakukan suatu pekerjaan. Karakteristik dasar menunjukkan bahwa kompetensi itu merupakan bagian dari kemampuan seseorang untuk bertahan (survival) dan dapat memprediksi perilakunya dalam situasi dan pekerjaan yang lebih luas. Sedangkan criterion referenced berarti bahwa kompetensi seseorang dapat memprediksi apakah kinerjanya baik atau jelek. Spencer dan Spencer (1993) juga memberikan lima karakteristik dasar dari kompetensi, yaitu : a) Motif (motive), sesuatu yang secara terus menerus dipikirkan atau diinginkan oleh seseorang yang menyebabkan adanya tindakan. Motif ini menggerakkan, mengarahkan dan memilih perilaku terhadap tindakan tertentu atau tujuan dan berbeda dari orang lainnya. b) Sifat (traits) karakteristik fisik dan respon yang konsisten terhadap situasi dan informasi. Konsep pribadi (self concept) perilaku, nilai-nilai dan kesan pribadi seseorang. d). Pengetahuan (knowledge) Informasi mengenai seseorang yang memiliki bidang substansi tertentu. e). Keterampilan (skill) Kemampuan untuk melaksanakan tugas fisik dan mental tertentu.

\section{Pengertian Kinerja}

Menurut Sedarmayanti mengungkapkan bahwa Kinerja merupakan terjemahan dari performance yang berarti P.ISSN: 1410-7988 E.ISSN: 2614-123X 
Hasil kerja seorang pekerja, sebuah proses manajemen atau suatu organisasi secara keseluruhan, dimana hasil kerja tersebut harus dapat ditunjukkan buktinya secara konkrit dan dapat diukur dibandingkan dengan standar yang telah ditentukan. Menurut Anwar Prabu Mangkunegara (2009) mengemukakan bahwa Kinerja adalah hasil kerja secara kualitas dan kuantitas yang dicapai oleh seorang pegawai dalam melaksanakan tugasnya sesuai dengan tanggung jawab yang diberikan kepadanya. Edy Sutrisno (2010) menyimpulkan kinerja sebagai hasil kerja karyawan dilihat dari aspek kualitas, kuantitas, waktu kerja, dan kerja sama untuk mencai tujuan yang sudah di tetapkan oleh organisasi. Menurut Mathis dan Jackson dalam Donni Juni Priansa (2014) menyatakan bahwa: "Kinerja pada dasarnya adalah apa yang dilakukan atau tidak dilakukan oleh pegawai dalam mengemban pekerjaannya". Menurut Benardin dan Russel dalam Donni Juni Priansa (2014), menyatakan bahwa : "Kinerja merupakan hasil yang di produksi oleh fungsi pekerjaan tertentu atau kegiatan-kegiatan pada pekerjaan tertentu selama periode waktu tertentu, yang memperlihatkan kualitas dan kuantitas dari pekerjaan tersebut".

Dari beberapa definisi di atas, dapat disimpulkan bahwa kinerja adalah hasil kerja seseorang atau sekelompok orang dalam suatu organisasi atau perusahaan secara kualitas dan kuantitas pada periode tertentu yang merefleksikan seberapa baik seseorang atau kelompok tersebut memenuhi persyaratan sebuah pekerjaan dalam usaha pencapaian tujuan organisasi atau perusahaan.

\section{HIPOTESIS PENELITIAN}

Diduga kompetensi berpengaruh dan signifikan terhadap kinerja Aparatur Sipil Negara (ASN) Kantor BAPPEDA Kota Pekanbaru.

\section{METODE}

\section{Lokasi Penelitian}

Lokasi penelitian bertempat di Kantor BAPPEDA Kota Pekanbaru, Riau, Indonesia.

Eko dan Bisnis (Riau Economics and Business Reviewe) Volume 11, Nomor 1, 27 Maret 2020

\section{Sumber Data Primer}

Sumber data primer merupakan sumber data yang didapat dan diolah secara langsung dari subjek yang berhubungan langsung dengan penelitian berupa data hasil pengisian kuisioner oleh Pegawai BAPPEDA kota Pekanbaru

\section{Sumber Data Sekunder}

Penggunaan data sekunder adalah sebagai penunjang yang menguatkan perolehan data hasil yang didapat dari artikel, internet, dan dokumen-dokumen yang dimiliki organisasi yang berkaitan dengan kegiatan penelitian

\section{Teknik Pengumpulan Data}

Kuesioner yaitu teknik pengumpulan data berdasarkan penyebaran lembaran pertanyaan yang disebut dengan angket. Semua pertanyaan dalam angket atau kuesioner tersebut disajikan dalam bentuk skala likert yang disesuaikan dengan pertanyaan tertutup, artinya diberikan kepada responden untuk menjawabnya (Sugiyono, 2010).

\section{Analisis Data}

Sesuai dengan masalah yang dikemukakan, maka untuk meneelah atau menentukan tingkat ketepatan permasalahan dalam penelitian ini, maka penelitian ini berbentuk kuantitatif bertolak dari studi pendahuluan dari objek yang diteliti (preliminary study) untuk mendapatkan yang betul-betul masalah (Sugiyono 2010). Penelitian ini pada prinsipnya adalah untuk menjawab masalah yang merupakan penyimpangan dari apa yang seharusnya dengan apa yang terjadi sesungguhnya, penyimpangan antara aturan dengan pelaksaan, teori dan praktek, perencanaan dengan pelaksanaan dan sebagainya.

\section{Metode Kuantitatif}

Menurut Roni Andespa (2012) analisis kuantitif adalah pengolahan data dengan kaidah-kaidah matematika terhadap data angka atau numeric. Angka dapat berupa representasi dari suatu kuantitas maupun angka hasil konversi dari suatu

P.ISSN: 1410-7988 E.ISSN: 2614-123X 
kualitas, yaitu data kualitatif yang di kuantifikasikan.

\section{Instrumen Penelitian Uji Validitas}

Meurut Sugiyono (2010) uji validitas digunakan untuk mengukur sah atau tidaknya suatu kuesioner. Suatu kuesioner dikatakan valid jika pertanyaan pada kuesioner mampu mengungkapkan sesuatu yang diukur oleh kuesioner tersebut. Validitas adalah suatu ukuran yang menunjukkan tingkat kevalidan dan kesahihan suatu instrument.

\section{Uji Reliabilitas}

Menurut

Sugiyono

menyatakan bahwa uji reliabilitas adalah alat ukur untuk suatu kuesioner yang merupakan indikator dari variabel. Suatu kuesioner dikatakan reliable atau handal jika jawaban seseorang terhadap pernyataan adalah konsisten atau stabil dalam waktu ke waktu. Reliabilitas dinyatakan koefisien reliabilitas yang angkanya berada dalam rentang dari 0 sampai dengan 1,00. Semakin tinggi koefisien reliabilitas mendekati angka 1,00 berarti semakin tinggi reliabilitas. Sebaliknya koefisien yang semakin rendah mendekati angka 0 berati semakin rendahnya reliabilitas. Batas minimal reliabilitas data secara umum adalah nilai Cronbach Alpha > 0,60 .

\section{Uji Normalitas Data}

Menurut Roni Andespa (2012), uji normalitas dilakukan dengan melihat kurva normal $\mathrm{p}=\mathrm{plot}$, suatu variabel dikatakan nornal jika gambar distribusi dengan titik data yang menyebar disekitar garis diagonal, dan penyebaran titik-titik searah mengikuti garis diagonal.

\section{Analisis Regresi Linier Sederhana}

Adapun dalam penelitian ini menggunakan teknik regresi linier sederhana. Menurut Sugiyono,(2010) digunakan untuk meramalkan bagaimana keadaan (naik turunnya) variabel dependen (kriterium), dengan variabel independen sebagai faktor prediktor dimanipulasi (dinaik turunkan nilainya). Pengujian ini dilakukan untuk melihat apakah ada pengaruh yang berarti apabila variabel bebas secara bersama terhadap variabel terikat. Untuk melihat pengaruh antara variabel dapat digunakan analisis regresi sederhana dengan berikut rumus :

$\mathrm{Y}=\mathrm{a}+\mathrm{bX}$

dimana :

$\mathrm{Y}=$ Kinerja (variabel terikat)

$\mathrm{X}=$ Kompetensi (variabel bebas)

$\mathrm{a}=$ Konstanta

$\mathrm{b}=$ Koefisien Regresi

\section{Uji Hipotesis}

Uji Hipotesis yang digunakan dalam penelitian ini adalah uji $t$ dan Koefisien Determinasi, berikut adalah penjelasan masing-masing uji hipotesis, yaitu :

\section{Uji parsial ( uji t )}

Uji ini digunakan untuk mengetahui signifikansi dari pengaruh variabel independen terhadap variabel dependen secara individual dan menganggap dependen yang lain konstan. Signifikansi pengaruh tersebut dapat diestimasi dengan membandingkan antara nilai $\mathrm{T}_{\text {tabel }}$ dengan nilai $\mathrm{T}_{\text {hitung. }}$.

$$
\text { Apabila nilai } \mathrm{T}_{\text {hitung }}>\mathrm{T}_{\text {tabel }} \text { maka }
$$
variabel independen secara individual mempengaruhi variabel independen, sebaliknya jika nilai $\mathrm{T}_{\text {hitung }}<\mathrm{T}_{\text {tabel }}$ maka variabel independen secara individual tidak mempengaruhi variabel dependen. $\mathrm{T}_{\text {hitung }}>$ $\mathrm{T}_{\text {tabel }}$ berarti $\mathrm{H}_{0}$ ditolak dan menerima $\mathrm{H}_{1}$. $\mathrm{T}_{\text {hitung }}<\mathrm{T}_{\text {tabel }}$ berarti $\mathrm{H}_{0}$ diterima dan menolak $\mathrm{H}_{1}$. Uji $\mathrm{T}$ juga bisa dilihat pada tingkat signifikansinya. Jika tingkat signifikansi $<0,05$, maka $\mathrm{H}_{0}$ ditolak dan $\mathrm{H}_{1}$ diterima. Jika tingkat signifikansi $>0,05$, maka $\mathrm{H}_{0}$ diterima dan $\mathrm{H}_{1}$ ditolak.

\section{Uji Determinasi}

Koefisien determinasi $\left(\mathrm{R}^{2}\right)$ bertujuan untuk mengetahui seberapa besar kemampuan variabel independen menjelaskan variabel dependen. Semakin besar nilai koefisien determinasi, maka semakin baik kemampuan variabel

$$
\text { P.ISSN: 1410-7988 E.ISSN: 2614-123X }
$$


independen menerangkan variabel dependen.

\section{HASIL}

Responden adalah pegawai BAPPEDA Kota Pekanbaru yang memberikan jawaban sesuai dengan ketentuan yang di berikan oleh peniliti dengan jumlah 50 responden.

\section{Tabel - 2}

\section{Profile Responden}

\begin{tabular}{|c|l|c|c|}
\hline \multirow{4}{*}{$\begin{array}{c}\text { Jenis } \\
\text { Kelamin }\end{array}$} & Pria & $\mathbf{2 2}$ & $\mathbf{4 4} \%$ \\
\cline { 2 - 4 } & Wanita & $\mathbf{2 8}$ & $\mathbf{5 6} \%$ \\
\hline \multirow{4}{*}{ Usia } & $20-29$ thn & 9 & $18 \%$ \\
\cline { 2 - 4 } & $30-39$ thn & 13 & $26 \%$ \\
\cline { 2 - 4 } & $40-49$ thn & 16 & $32 \%$ \\
\cline { 2 - 4 } & $>50$ thn & 12 & $24 \%$ \\
\hline \multirow{4}{*}{ Pendidikan } & SMA & $\mathbf{8}$ & $\mathbf{1 6} \%$ \\
\cline { 2 - 4 } & D1-D3 & $\mathbf{3}$ & $\mathbf{6 \%}$ \\
\cline { 2 - 4 } & $\mathbf{S - 1}$ & $\mathbf{2 4}$ & $\mathbf{4 8} \%$ \\
\cline { 2 - 4 } & $\mathbf{S - 2}$ & $\mathbf{1 5}$ & $\mathbf{3 0} \%$ \\
\hline \multirow{4}{*}{$\begin{array}{c}\text { Lama } \\
\text { Bekerja }\end{array}$} & 4-7 tahun & 6 & $12 \%$ \\
\cline { 2 - 4 } & $8-10$ tahun & 9 & $18 \%$ \\
\cline { 2 - 4 } & $>10$ tahun & 30 & $60 \%$ \\
\hline
\end{tabular}

Sumber : Olahan Data, 2020

\section{Uji Validitas}

Tabel - 3

Kompetensi (X)

\begin{tabular}{|c|c|c|c|c|}
\hline \multirow{4}{*}{ Variabel } & $\begin{array}{c}\text { No. } \\
\text { Item }\end{array}$ & $\mathbf{r}$ hitung & $\begin{array}{c}\mathbf{r} \\
\text { tabel }\end{array}$ & Ket \\
\hline \multirow{4}{*}{$\begin{array}{c}\text { Kompetensi } \\
(X)\end{array}$} & 1 & 0,773 & 0,279 & Valid \\
\cline { 2 - 5 } & 2 & 0,642 & 0,279 & Valid \\
\cline { 2 - 5 } & 3 & 0,457 & 0,279 & Valid \\
\cline { 2 - 5 } & 4 & 0,565 & 0,279 & Valid \\
\cline { 2 - 5 } & 6 & 0,540 & 0,279 & Valid \\
\cline { 2 - 5 } & 7 & 0,521 & 0,279 & Valid \\
\cline { 2 - 5 } & 8 & 0,580 & 0,279 & Valid \\
\cline { 2 - 5 } & 9 & 0,697 & 0,279 & Valid \\
\cline { 2 - 5 }
\end{tabular}

Eko dan Bisnis (Riau Economics and Business Reviewe) Volume 11, Nomor 1, 27 Maret 2020

\begin{tabular}{|l|l|l|l|}
\hline 10 & 0,421 & 0,279 & Valid \\
\hline 11 & 0,462 & 0,279 & Valid \\
\hline 12 & 0,577 & 0,279 & Valid \\
\hline 13 & 0,662 & 0,279 & Valid \\
\hline 14 & 0,408 & 0,279 & Valid \\
\hline 15 & 0,706 & 0,279 & Valid \\
\hline 16 & 0,709 & 0,279 & Valid \\
\hline 17 & 0,667 & 0,279 & Valid \\
\hline 18 & 0,651 & 0,279 & Valid \\
\hline 19 & 0,662 & 0,279 & Valid \\
\hline 20 & 0,308 & 0,279 & Valid \\
\hline 21 & 0.791 & 0,279 & Valid \\
\hline 22 & 0,682 & 0,279 & Valid \\
\hline 23 & 0,688 & 0,279 & Valid \\
\hline 24 & 0,763 & 0,279 & Valid \\
\hline 25 & 0,734 & 0,279 & Valid \\
\hline 26 & 0,613 & 0,279 & Valid \\
\hline 27 & 0,530 & 0,279 & Valid \\
\hline 28 & 0,641 & 0,279 & Valid \\
\hline 0
\end{tabular}

Sumber : Data olahan SPSS

Pada tabel 3 diatas, item akan dinyatakan valid jika memiliki nilai $\boldsymbol{r}_{\text {hitung }}>$ $r_{\text {tabel }}$. Hasil Uji dengan SPSS menunjukkan seluruh item pernyataan variabel kinerja memiliki $r_{\text {hitung }}>r_{\text {tabel }}(0,279)$. Maka dapat di simpulkan bahwa seluruh item pernyataan variabel kompetensi dinyatakan valid.

Tabel - 4

Kinerja (Y)

\begin{tabular}{|c|c|c|c|c|}
\hline \multirow{4}{*}{ Variabel } & $\begin{array}{c}\text { No. } \\
\text { Item }\end{array}$ & $\begin{array}{c}\mathbf{r} \\
\text { hitung }\end{array}$ & r tabel & Ket \\
\hline \multirow{4}{*}{$\begin{array}{c}\text { Kinerja } \\
(Y)\end{array}$} & 1 & 0,791 & 0,279 & Valid \\
\cline { 2 - 5 } & 2 & 0,582 & 0,279 & Valid \\
\cline { 2 - 5 } & 3 & 0,668 & 0,279 & Valid \\
\cline { 2 - 5 } & 4 & 0,610 & 0,279 & Valid \\
\cline { 2 - 5 } & 5 & 0,692 & 0,279 & Valid \\
\cline { 2 - 5 } & 6 & 0,685 & 0,279 & Valid \\
\hline
\end{tabular}

P.ISSN: 1410-7988

E.ISSN: 2614-123X 


\begin{tabular}{|l|c|c|c|c|}
\hline \multirow{7}{*}{} & 7 & 0,691 & 0,279 & Valid \\
\cline { 2 - 5 } & 8 & 0,662 & 0,279 & Valid \\
\cline { 2 - 5 } & 9 & 0,809 & 0,279 & Valid \\
\cline { 2 - 5 } & 10 & 0,747 & 0,279 & Valid \\
\hline
\end{tabular}

Sumber : Data olahan SPSS

Pada tabel 4 diatas, item akan dinyatakan valid jika memiliki nilai $\boldsymbol{r}_{\text {hitung }}>$ $\boldsymbol{r}_{\text {tabel }}$. Hasil uji dengan SPSS menunjukkan seluruh item pernyataan variabel disiplin memiliki $\boldsymbol{r}_{\text {hitung }}>\boldsymbol{r}_{\text {tabel }}(0,279)$. Maka dapat disimpulkan bahwa seluruh item pernyataan variabel kinerja dinyatakan valid.

\section{Uji Reliabilitas}

Reliabilitas dapat diartikan sebagai keteran dalam atau dapat dipercaya. Instrumen yang reliabel berarti instrumen tersebut jika digunakan beberapa kali untuk mengukur objek yang sama, akan menghasilkan data yang sama. Nilai reliabilitas terdapat pada kolom Cronbach's Alpha, yaitu suatu variabel dianggap reliabel jika nilai Cronbach's Alpha di atas 0,60. Hasil Pengujian reliabilitas angket adalah sebagai berikut :

Tabel - 5

Uji Reliabilitas

\begin{tabular}{|c|c|c|c|}
\hline Variabel & $\begin{array}{c}\text { Cronbach's } \\
\text { Alpha }\end{array}$ & $\begin{array}{c}\text { Nilai } \\
\text { Reliabe } \\
\mathbf{l}\end{array}$ & Ket \\
\hline $\begin{array}{c}\text { Kompetensi } \\
(\mathrm{X})\end{array}$ & 0,946 & 0,60 & Reliabel \\
\hline Kinerja (Y) & 0,875 & 0,60 & Reliabel \\
\hline
\end{tabular}

Sumber : Data olahan SPSS

Dari tabel 5 dapat dilihat bahwa Cronbach's Alpha pada masing-masing variabel yaitu Lingkungan Kerja $(0,946)$, dan Variabel Kinerja $(0,875)$ memiliki nilai Cronbach's Alpha diatas 0,60. Artinya bahwa setiap item variabel yang digunakan dalam penelitian ini memiliki kehandalan atau reliabel.

\section{Uji Normalitas}

Uji normalitas digunakan untuk memngetahui apakah sampel data berdistribusi normal tidak. Uji ini biasanya

Eko dan Bisnis (Riau Economics and Business Reviewe) Volume 11, Nomor 1, 27 Maret 2020 digunakan untuk mengukur data berskala ordinal, interval ataupun rasio. Berikut adalah hasil uji normalitas pada SPSS sebagaimana dapat dilihat pada gambar 5.1 berikut ini :

\section{Gambar 1}

\section{Hasil Uji Normalitas}

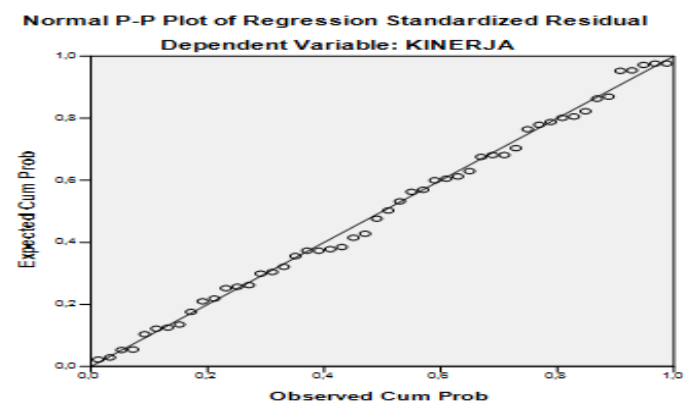

Sumber : Data Olahan SPSS

Dari gambar 1 diatas, dapat dilihat bahwa data penyebar disekitar garis diagonal dan mengikuti arah garis diagonal, maka dengan demikian dapat disimpulkan model regresi memenuhi asumsi normalitas.

\section{Regresi Linier Sederhana}

Untuk mengetahui pengaruh lingkungan kerja digunakan analisis statistik dengan regresi linier sederhana. Untk pengolahan data penelitian dilakukan dengan menggunakan program pengolahan data SPSS (Statistic Package Social Science) dengan $\alpha=0,05$ yang dapat dilihat pada tabel berikut :

\section{Tabel - 6}

\section{Hasil Uji Regresi Linier Sederhana}

Sumber : Data olahan SPSS

Berdasarkan hasil dari pengolahan data yang disajikan pada tabel 6 diatas,

Coefficients $^{\text {a }}$

\begin{tabular}{|c|c|c|c|c|c|c|}
\hline \multirow[b]{2}{*}{ Model } & & \multicolumn{2}{|c|}{ Unstandardized Coefficients } & \multirow{2}{*}{$\begin{array}{c}\begin{array}{c}\text { Standardized } \\
\text { Coefficients }\end{array} \\
\text { Beta }\end{array}$} & \multirow[b]{2}{*}{$t$} & \multirow[b]{2}{*}{ Sig. } \\
\hline & & B & Sto. Error & & & \\
\hline \multirow[t]{2}{*}{1} & (Constant) & 14,104 & 3,706 & & 3,806 &, 000 \\
\hline & KOMPETENSI & 217 &, 030 &, 722 & 7,234 &, 000 \\
\hline
\end{tabular}

a. Dependent Variable: KINERJA

maka di dapat persamaan regresi linier sederhana sebagai berikut :

$\mathrm{Y}=\mathrm{a}+\mathrm{bx}$

dimana 
$Y=14,104+0,217 x$

Persamaan regresi tersebut dapat dijelaskan sebagai berikut :Nilai konstanta (a) $=1,201$ ini menyatakan bahwa variabel Lingkungan kerja (X) dianggap konstan atau nol (0) maka kinerja (Y) adalah sebesar 14,104. dan nilai koefisien (b) $=0,217$ artinya jika lingkungan kerja mengalami kenaikan sebesar 1 satuan, koefisien bernilai positif, artinya terjadi pengaruh yang positif antara kompetensi dengan kinerja, jika semakin besar nilai kompetensi maka semakin meningkat nilai kinerja.

\section{Hasil Uji t}

Nilai $\mathrm{t}$ tabel dilihat pada tabel $\mathrm{t}$ dengan df $\mathrm{n}-\mathrm{k}-\mathrm{l}$; 50-1-1=48, sehingga didapat nilai ttabel 2,03951 maka dari tabel 4 diperoleh nilai thitung $(7,234)$ lebih besar nilai tabel $(1,6772)$ dengan tingkat signifikan $0,000<0,050$. Maka dapat disimpulkan bahwa $\mathrm{H}_{0}$ ditolak dan $\mathrm{H}_{\mathrm{a}}$ diterima, yang artinya kompetensi berpengaruh signifikan terhadap kinerja pegawai ASN BAPPEDA Kota Pekanbaru.

\section{Koefisien Determinasi (R2)}

Koefisien determinasi (R2) digunakan untuk mengetahui besarnya persentase sumbangan atau kontribusi variabel bebas kompetensi (X) terhadap variabel terikat kinerja (Y). Hasil koefisien determinasi dapat kita lihat pada tabel dibawah ini :

Tabel - 7

\section{Koefisien Determinasi (R2)}

Model Summary $b$

\begin{tabular}{l|r|r|r|r|}
\hline Model & $\mathrm{R}$ & $\mathrm{R}$ Square & $\begin{array}{c}\text { Adjusted R } \\
\text { Square }\end{array}$ & $\begin{array}{r}\text { Std. Error of } \\
\text { the Estimate }\end{array}$ \\
\hline 1 &, $722^{\mathrm{a}}$ &, 522 &, 512 & 2,79033 \\
\hline
\end{tabular}
a. Predictors: (Constant), KOMPETENSI
b. Dependent Variable: KINERJA

\section{Sumber : Data Olahan SPSS}

Berdasarkan perhitungan pada tabel 7 diperoleh nilai $\mathrm{R}$ square sebesar 0,522 atau $52,2 \%$ maka persentase sumbangan atau kontribusi variabel bebas terhadap variabel terikat sebesar 0,522 atau 52,2\% sedangkan Eko dan Bisnis (Riau Economics and Business Reviewe) Volume 11, Nomor 1, 27 Maret 2020 sisanya sebesar 47,8\% dipengaruhi oleh variabel lain yang diabaikan atau tidak diteliti dalam penelitian ini.

\section{SIMPULAN}

Berdasarkan hasil penelitian dapat disimpulkan :

1. Adanya pengaruh yang signifikan antara kompetensi terhadap kinerja pegawai ASN BAPPEDA Kota Pekanbaru, dengan nilai t-hitung sebesar 7,234 lebih besar dari nilai t-tabel 1,6772 dengan nilai sig $<0,05$.

2. Pada Hasil uji koefisien determinasi menunjukan bahwa nilai $\mathrm{R}$ square (R2) adalah sebesar 0,522 hal ini menunjukan bahwa variabel lingkungan kerja menyumbangkan sebesar 52,2\%, sedangkan sisanya sebesar $47,8 \%$ dipengaruhi oleh faktor lain.

\section{DAFTAR RUJUKAN}

Ajib Rakhmawanto (2007) (Jurnal) Pengembangan Sistem Manajemen Aparatur Sipil Negara Berbasis Teknologi Informasi: Analisis Implementasi dan Hambatan

Andespa, Roni. 2012. Metodelogi Penelitian Bisnis. Pekanbaru: Al-huda Press.

A.A. Anwar Prabu Mangkunegara. (2009). Manajemen Sumber Daya Manusia. Bandung: PT. Remaja Rosdakarya.

Arikunto. (2010). Prosedur Penelitian: Suatu Pendekatan Praktek. Jakarta: Rineka Cipta.

Donni Junni Priansa 2014, Perencanaan \& Pengembangan SDM, Penerbit Bandung: Alfabeta.

Mathis, Robert L. dan John H. Jackson. (2012). Manajemen Sumber Daya Manusia, Edisi Pertama Salemba Empat, Jakarta.

Rothwell W, J. (2000). Models of human performance improvement. Second Edition, Elsevier.

Sedarmayanti. 2009. Sumber Daya Manusia dan Produktivitas Kerja. Bandung: CV Mandar Maju.

\footnotetext{
P.ISSN: 1410-7988 E.ISSN: 2614-123X
} 
Sugiyono. 2010. Metode Penelitian

Kuantitatif Kualitatif \& RND. Bandung : Alfabeta.

Sutrisno, Edy. 2009, Manajemen Sumber Daya Manusia, Jakarta,Kencana Pernada Media Group.

S.P,Hasibuan, Malayu. 2013. Manajemen Sumber Daya Manusia. Jakarta: PT Bumi Aksara.

Spencer, L. M., dan Spencer, S.M (1993).

Competence at Work. New York :

Wiley

Peraturan Daerah Kota Pekanbaru Nomor 9

Tahun 2016 tentang Pembentukan dan

Susunan Perangkat Daerah Kota Pekanbaru

Peraturan Walikota Pekanbaru Nomor 116 Tahun 2016 tentang Kedudukan, Susunan Organisasi, Tugas dan Fungsi serta Tata Kerja Badan Perencanaan Pembangunan Daerah Kota Pekanbaru

Undang-undang No. 5 Tahun 2014 tentang Aparatur Sipil Negara (ASN) 